\title{
Comparative study between standard and inside-out vein graft techniques on sciatic nerve repair of rats. Muscular and functional analysis ${ }^{1}$
}

Cleuber Rodrigo de Souza BuenoI, Mizael Pereira ${ }^{\mathrm{II}}$, Idvaldo Aparecido Favaretto-Júnior ${ }^{\mathrm{III}}$, Rogerio Leone Buchaim ${ }^{\mathrm{IV}}$, Jesus Carlos Andreov ${ }^{\mathrm{V}}$, Antônio de Castro Rodrigues ${ }^{\mathrm{VI}}$, Geraldo Marco RosaJúnior $\mathrm{VII}$

'Graduate student, Department of Biological Sciences, Universidade do Sagrado Coração (USC), Bauru-SP, Brazil. Technical procedures; acquisition, analysis and interpretation of data; histopathological examinations; manuscript preparation.

"MSc, Department of Biological Sciences (Anatomy), Faculdade de Odontologia de Bauru, Universidade de São Paulo (FOB-USP), Bauru-SP, Brazil. Analysis and interpretation of data, histopathological examinations, manuscript preparation and writing.

'"MSc, Department of Biological Sciences (Anatomy), FOB-USP, Bauru-SP, Brazil. Acquisition of data, technical procedures.

IVPD, Associate Professor, Department of Biological Sciences (Anatomy), FOB-USP, Bauru-SP, Brazil. Scientific and intellectual content of the study, statitics analysis.

${ }^{\vee}$ PhD, Full Professor, Department of Biological Sciences (Anatomy), FOB-USP, Bauru-SP, Brazil. Scientific and intellectual content of the study.

VIPhD, Associate Professor, Department of Biological Sciences (Anatomy), FOB-USP, Bauru-SP, Brazil. Conception, design, scientific and intellectual content of the study; final approval.

VIIPhD, Associate Professor, Department of Biological Sciences, USC, Bauru-SP, Brazil. Conception and design of the study, critical revision, final approval.

\section{Abstract}

Purpose: To compare the functional result of standart vein grafts and inside-out vein graft technique on sciatic nerve repair.

Methods: We used 24 male Wistar rats divided into 4 groups: control group (CG), standard vein graft group (SVG), Inside-out vein graft group (IOVG) and denervated Group (DG). SVG, IOVG and DG underwent total section of the sciatic nerve, SVG and IOVG however underwent nerve repair surgery using a graft with normal jugular vein and inside-out jugular vein, respectively. Histological analysis of the soleus and Extensor Digitorum Longus (EDL), and Sciatic Functional Index were used to compare the results after 6 weeks.

Results: Both grafts acted favorably in muscle recovery and improved functionality; They were similar in all parameters, however, in more points SVG achieved similar to the CG, in the other hand IOVG more times was similar to DG. Fact that makes the graft with normal vein the most viable option between the two options.

Conclusion: Both types of grafts acted beneficially wherein the graft normal vein has proved to be the best option

Key words: Peripheral Nerves. Sciatic Nerve. Nerve Regeneration. Muscle, Skeletal. Rats. 


\section{Introduction}

Peripheral nerve lesions with loss of nervous tissue (neurotmesis) are common and always cause impairment of the sensibility and motility of parts of the organism ${ }^{1,2}$ and a negative impact on the social sphere and social security.

Acute peripheral nerve injuries are one of the complications of trauma affecting the extremities, and is present in $3-10 \%$ of patients, depending on the mechanism of trauma ${ }^{3}$. Common causes of peripheral nerve injuries are projectiles of firearms, falls, trauma, injury by penetrating objects and mainly by car accidents ${ }^{4}$, and approximately $\$ 150$ billion dollars are spent annually in health-care with nerve injuries in the United States ${ }^{3}$.

According to Seddon ${ }^{5}$, neurotmesis (total nerve rupture) is the most severe injury to the peripheral nerve, and in this type of trauma surgical repair is essential for the rehabilitation of function.

The gold standard treatment for peripheral nerve repair is the autologous nerve graft with the aid of a surgical microscope. Although this technique has a favorable result, it presents as main negative factors: the limitation of calibers, lengths and areas of donor nerves and secondary morbidity ${ }^{6-8}$.

In this sense, the tubulization technique has been shown to be an appropriate and alternative method in clinical practice, which consists of the fixation of a tubular segment, which may be of biological or synthetic origin, between the stumps of the injured nerve, providing direction and favorable environment to regeneration ${ }^{9,10}$.

Several authors defend the use of venous grafts in the repair of peripheral nerve gaps, justified by the ease of access without damage to the patient, abundance of calibers and donor sites, besides not presenting a financial $\operatorname{cost}^{11-13}$.
For this purpose, the adhesion of the rat as an animal model was based on the fact that its physiological profile, its morphological structure and the biological processes involved in the nerve regeneration are quite similar to that of the human being, being a suitable model for this investigation ${ }^{14}$.

The purpose of this study was to compare the muscular and functional results after sciatic nerve repair with the tubulization technique using the normal vein graft and the reverse vein graft, in order to determine the most favorable surgical option.

\section{Methods}

The study was approved under the protocol $032 / 2011$ by the Ethics Committee, Faculty of Dentistry of Bauru, Universidade de São Paulo. Were used twenty-four male Wistar rats with 60 days of life in collective storage, with no restrictions on movement, respecting cycles of 12 hours of light / dark and average ambient temperature of $24^{\circ} \mathrm{C}$.

The animals were divided into four groups ( $n=6$ each). Control Group (CG) and three experimental groups: Denervate Group (DG), Inside-Out Vein Graft (IOVG) and Standart Vein Graft (SVG). In all groups the right pelvic limb was used for the experimental study. The IOVG and SVG groups received autologous venous graft from the left jugular vein, but for the IOVG group, the jugular vein was inverted.

\section{Surgical procedures}

The animals were anesthetized with a combination of Ketamine Hydrochloride (Dopalen ${ }^{\circ}$ and Xilazine Hydrochloride (Anasedan ${ }^{\circ}$ ), administered intramuscularly at a dose of $0.10 \mathrm{ml} / 100 \mathrm{~g}$ body weight in the dorsolateral region of the left hind paw. Subsequently, the tricotomy was performed on the left ventral face of the neck in all animals and cleansed the site with antiseptic solution, 
followed by incision of the skin and dissection of a $15 \mathrm{~mm}$ segment of the left external jugular vein. The vein was maintained in saline solution until the moment of its use as a graft between the nerve stumps. Then, the tricotomy of the right hind paw of the animal was performed and a lateral dorsal incision of the pelvic limb was made for access to the sciatic nerve.

The CG animals received only the incision in the posterior region of the right paw and had the musculature divulsion until the exposure of the sciatic nerve. However, it did not receive any intervention in the nerve and served as control of the experiment, being submitted only to the same surgical stress of the other animals. DG underwent surgery to section the sciatic nerve. In order to avoid spontaneous regeneration, the proximal stump was manipulated 180 degrees and sutured in the adjacent muscular fascia, while the distal stump was manipulated 180 degrees and sutured in the adjacent musculature. IOVG animals, after sectioning and removing a $10 \mathrm{~mm}$ gap from the right sciatic nerve, received the external jugular vein graft to the reverse, and raffia was performed through the epineurium with two simple points using 10-0 nylon suture wire. The SVG group received the external jugular vein as graft, however without its inversion and was sutured in a manner similar to that performed in the IOVG.

After the 6-week post-operative period, the animals of all groups underwent functional evaluation by Sciatic Functional Index (SFI) except the animals of the DG.

\section{Sciatic functional index}

To perform the the sciatic functional index (SFI), the animals walked through a transparent acrylic walkway where the footprints on the floor were filmed and transformed into an image by software Free Video to JPG v.5.0.20 (DVD Video Soft Limited,
LONDON, UNITED KINDGOM). For the analysis, the reference measurements and the equation described by Bain, Mackinon and Hunter ${ }^{15}$ were followed. The measurements were performed using Image Pro-Plus ${ }^{\circ} 6.2$ software (Media Cybernetics, Bethesda, MD, USA) using the values obtained for the calculation of the equation, the resulting value being accepted as a regression index of the nerve, and animals with normal sciatic nerve function present values closer to zero.

\section{Sampling and muscle weight}

After the IFC measurement, another surgical moment was performed. In this second intervention the samples were removed and weighed. Animals were anesthetized following the same anesthesia protocol of the first surgery. After anesthesia, the EDL and soleus muscles of each animal of all groups were dissected. Removal was done from the distal insertion until its proximal insertion of the muscle, so that its integrity was maintained. Each sample was carefully weighed before cryopreservation protocol.

\section{Euthanasia}

Animals were killed through an anesthetic overdose of Ketamine Hydrochloride (Dopalen ${ }^{\circ}$ and Xilazine Hydrochloride (Anasedan ${ }^{\circ}$ ) for removal of the soleus and longus extensor (EDL) muscles.

\section{Histological processing}

For cryopreservation, the samples of the Soleus (SO) and Extensor Digitorum Longus (EDL) muscles were reduced to cylindrical fragments, after which the Optimal Critical Temperature Tissue-Tek $^{\circ}$ gel (OCT, Sakura Finetek, Torrance, USA) was used for inclusion and then the samples were submerged in liquid nitrogen for instant freezing and then stored in a freezer at 
$-80^{\circ} \mathrm{C}$. Histological sections were obtained in a Leica cryostat - Model CM 1850 at $-20^{\circ} \mathrm{C}$ and stained with Hematoxylin and Eosin (HE) and Masson's trichrome for morphometric analysis.

\section{Morphometric analysis}

\section{Cross-sectional area and minimum diameter}

The images were captured with a photomicroscope Olympus BX 50, coupled to the computer and three different fields of each sample were photographed with $20 x$ objective. For morphometric analysis 220 muscle fibers of each animal was manually measured, area and the Minimum diameter, through Image Pro-Plus ${ }^{\circ} 6.2$ program (Media Cybernetics, Bethesda, MD, USA).

\section{Density of connective tissue}

Using Masson's trichrome staining, a photo of the cross-sectional area of the entire muscle was captured using a $\times 2$ objective to measure its total area, and then $\times 20$ objective photos were captured for the software Image ProPlus 6.2 to recognize Aniline Blue (responsible for marking connective tissue in this technique) with more fidelity. After the measurements, the calculation was made to obtain the percentage of connective tissue in the muscle.

\section{Statistical analysis}

For statistical analysis of muscle weight, muscle fiber morphometry, connective tissue morphometry and functional index, the groups were compared by the analysis of variance (ANOVA) and when this analysis detected a significant difference, the Tukey tests were applied for the comparisons between the means. Was considered $p \leq 0.05$.

\section{- Results}

\section{Muscle weight}

In our study, we observed a rapid loss of muscle weight after denervation, a fact observed in the denervated group for 6 weeks, (DG). It was also observed that the operated groups (SVG, IOVG) had higher muscle weight values than the denervated group, but there was no statistically significant difference (Figure 1, Table 1).
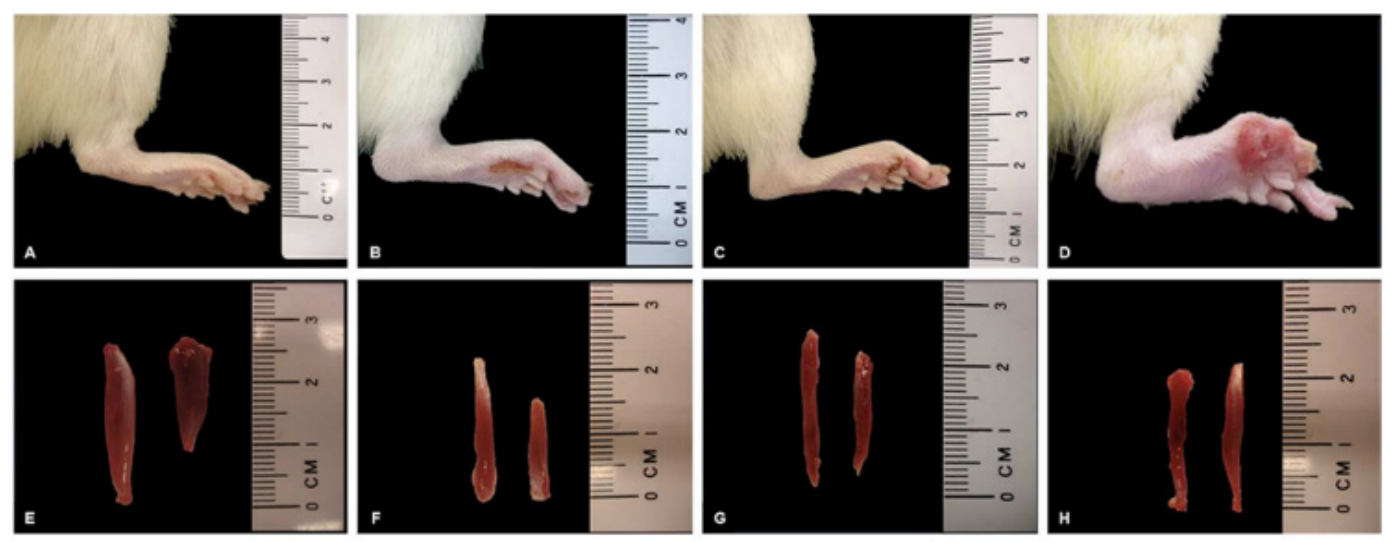

Figure 1 - Photographs representative of the groups: Animal hindlimb (A-D) and EDL and soleus muscles, left and right respectively (E-H). The CG images are $(\mathbf{A}, \mathbf{E})$, SVG $(\mathbf{B}, \mathbf{F})$, IOVG $(\mathbf{C}, \mathbf{G})$ and $D G(\mathbf{D}, \mathbf{H})$. 
Table 1 - Muscle weight of the soleus and EDL muscles of the groups.

\begin{tabular}{lllll}
\multicolumn{5}{c}{ Muscle Weight (g) } \\
& Soleus & & EDL \\
& Mean & SD & Mean & SD \\
\hline CG & $0.19^{\mathrm{a}}$ & \pm 0.02 & $0.18^{\mathrm{a}}$ & \pm 0.02 \\
DG & $0.04^{\mathrm{b}}$ & \pm 0.002 & $0.04^{\mathrm{b}}$ & \pm 0.01 \\
SVG & $0.06^{\mathrm{b}}$ & \pm 0.01 & $0.07^{\mathrm{b}}$ & \pm 0.02 \\
IOVG & $0.06^{\mathrm{b}}$ & \pm 0.007 & $0.06^{\mathrm{b}}$ & \pm 0.01 \\
\hline
\end{tabular}

*Distinct letters indicate statistical significance $(p<0.05)$.

\section{Morphological analysis of muscle fibers and connective tissue density}

In the histological observations, CG is found in both the EDL and soleus muscle, polygonal muscle fibers, with peripheral nuclei, normal fascicular pattern, with organized histological architecture evidencing the normal morphology of skeletal muscle tissue.

On the other hand, DG presents a great invasion of connective tissue, centralized nuclei, fibers with small diameter, which are characteristic of muscle fibers in the process of atrophy by denervation.

IOVG and SVG groups presented morphological similarity to each other, and a great histological improvement when compared to the DG, although it still has some centralized nuclei and a small fascicular disorganization if compared to CG (Figure 2).
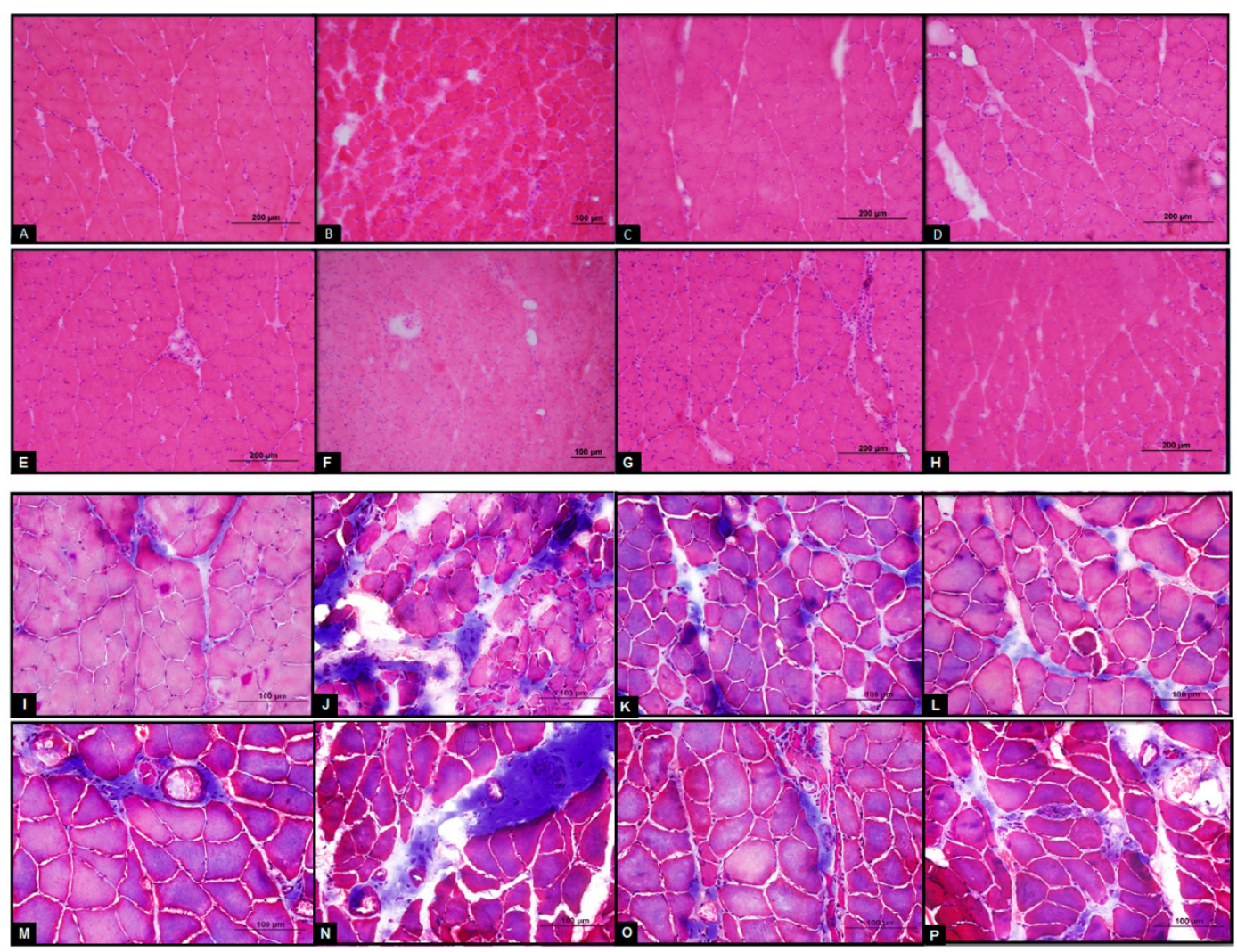

Figure 2 - Representative images of the muscles stained in HE: Soleus (A-D) and EDL (E-H) and Masson's Trichrome: Soleus (I-L) and EDL (M-P). The images for CG are (A,E,I,M), DG (B,F,J,N), SVG $(\mathbf{C}, \mathbf{G}, \mathbf{K}, \mathbf{O})$ and IOVG $(D, H, L, P)$. The images of the sections stained in $\mathrm{HE}$ were obtained with the $20 \mathrm{x}$ objective and the sections stained in Tricromic captured with a x40 objective. 
Morphometric analysis of cross-sectional area and minimum diameter of muscle fibers

In the soleus muscle, it was observed that: in both the cross-sectional area and the minimum diameter of the fibers, the CG group obtained the highest mean in counterpart, the lowest mean was the DG group. In the comparison between the experimental groups, IOVG and SVG, there was an ambiguity between the groups, with results very close to each other. The IOVG and SVG groups presented areas of the fibers with values closer to the DG group and the SVG had a slight area advantage (Table 2).

In the EDL muscle, CG obtained a mean fiber area and minimum diameter superior to all experimental groups. The IOVG and SVG groups present a mean fiber area and minimum diameter with values closer to the DG than to the CG, and in the comparison between the experimental groups, IOVG and SVG presented results very close to each other, but in the variable Minimum diameter, only statistically significant IOVG in relation to DG (Table 2).

Table 2 - Mean of fiber area and minimum diameter in the soleus and EDL muscles.

\begin{tabular}{lllllllll}
\hline & \multicolumn{3}{l}{ Fiber area } & \multicolumn{5}{c}{ Minimum diameter } \\
& Soleus & & EDL & & \multicolumn{3}{c}{ Soleus } & \multicolumn{3}{c}{ EDL } \\
& Mean & SD & Mean & SD & Mean & SD & Mean & SD \\
\hline CG & $3326.98^{\mathrm{a}}$ & \pm 726.09 & $2001.64^{\mathrm{a}}$ & \pm 629.32 & $49.63^{\mathrm{a}}$ & \pm 7.65 & $39.2^{\mathrm{b}}$ & \pm 6.91 \\
DG & $503.96^{\mathrm{b}}$ & \pm 371.56 & $519.48^{\mathrm{b}}$ & \pm 482.33 & $14.96^{\mathrm{c}}$ & \pm 13.28 & $15.68^{\mathrm{a}}$ & \pm 11.03 \\
SVG & $957.47^{\mathrm{b}}$ & \pm 341.55 & $1039.96^{\mathrm{b}}$ & \pm 318.22 & $26.56^{\mathrm{b}}$ & \pm 5.98 & $27.58^{\mathrm{c}}$ & \pm 5.24 \\
IOVG & $905.89^{\mathrm{b}}$ & \pm 282.39 & $879.9^{\mathrm{b}}$ & \pm 277.77 & $25.75^{\mathrm{b}, \mathrm{c}}$ & \pm 5.24 & $25.89^{\mathrm{c}}$ & \pm 5.00 \\
\hline
\end{tabular}

* Distinct letters indicate statistical significance $(p<0.05)$.

Analysis of the connective tissue density

The percentage of connective tissue in CG was the lowest in both muscles. On the other hand, the percentage of DG was the largest of the groups, also in both muscles. The IOVG and SVG groups had a percentage of connective tissue above the CG and below the DG in both; in the comparison between IOVG and SVG, there was a higher percentage of connective tissue in the IOVG group, but this difference was not statistically significant for any of the muscles (Table 3).

Table 3 - Density of connective tissue in soleus and EDL muscle.

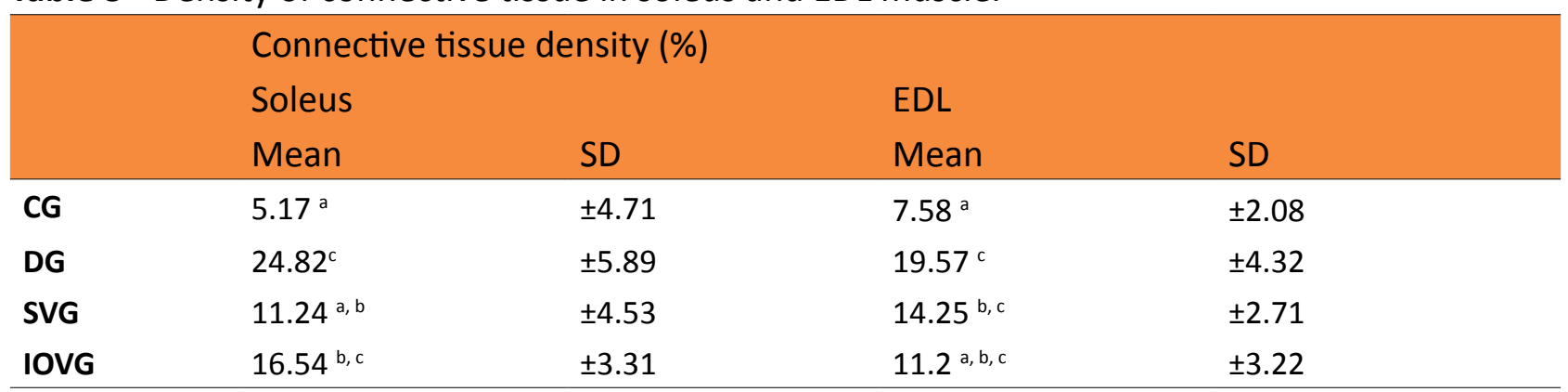

* Distinct letters indicate statistical significance $(p<0.05)$. 


\section{Sciatic functional index}

The best index seen, as expected, was that of CG. The DG does not present sciatic functional index values once it has undergone denervation. Between SVG and IOVG the difference was not statistically significant (Table 4).

Table 4 - Sciatic functional índex of the animals with 6 weeks post-surgery.

\begin{tabular}{lll} 
& \multicolumn{2}{l}{ Sciatic functional index } \\
& Mean & SD \\
\hline DG & -- & -- \\
CG & $-22.89^{\text {a }}$ & 16.35 \\
SVG & $-94.91^{\text {b }}$ & 13.77 \\
IOVG & $-109.64^{\text {b }}$ & 6.5 \\
\hline
\end{tabular}

*Distinct letters indicate statistical significance $(p<0.05)$.

\section{Discussion}

This study was designed with the purpose of evaluating the influence of normal vein graft and inside-out vein graft on sciatic nerve repair, evaluating which delivery best functional and morphological result for the model of nerve injury adopted.

In sectioned nerves, the first option of repair is the end-to-end neurorraphy, joining the stumps through suture or through adhesives (e.g fibrin glue $)^{7,16}$. In some cases, according to the extension of the lesion, it is not possible unite the stumps and suture them without causing tension to the nerve, fact that occurs mainly when this rupture involves the loss of tissue. In these cases the "gold standard" is autologous nerve graft, however, it has some disadvantages, such as loss of a healthy nerve, risk of neuromas formation, and limited availability of donor material ${ }^{17}$.

Therefore, the use of autologous venous graft for nerve repair is a good option due to its low cost, non-rejection (even donor and recipient) and not presenting autologous nerve graft morbidity in donor nerve removal, being able to regenerate the Sciatic nerve and thus the structures innervated ${ }^{7,8}$. This advantage was also reported by Demir et al. ${ }^{18}$, who compared the use of the vein to that of a synthetic collagen tube in a $10 \mathrm{~mm}$ gap, and concluded that both, Tube of synthetic collagen and autologous vein grafts, produced similar results, however, with vein grafting being slightly more effective.

The involvement of the cells derived from the blood vessels in the microenvironment contributes positively to the regeneration of the nerve. This fact was evidenced by Lavasani et $a .^{19}$ when comparing the use of a normal vein and a decellularized vein, where the result showed a very poor regeneration in the tubularized group with the decellularized vein when compared to the normal vein, demonstrating that the presence of Cells in the vein contributes positively to nerve regeneration.

In the literature, there are studies that used the normal vein ${ }^{18,20}$, and studies using the inverted vein $^{21-23}$, the choice of protocol varies according to the author. However, Sabongi et al. ${ }^{24}$ argue that the normal vein may have valves that can cause lumen obstruction, whereas the use of the inverted vein graft avoids such disadvantage and places the adventitial surface of the vessel (which is rich in collagen and laminin) in contact with the nerve thus providing a better condition to regenerate. In our study, however, this was not a factor capable of inducing significant change in any of the variables when comparing SVG vs IOVG.

In all groups submitted to the section of the sciatic nerve the loss of muscle mass was evident. We could observe by means of the muscular weight, in which SVG, IOVG and DG were inferior to the CG and statistically similar to each other. However, muscle weight alone can not indicate muscle quality in an absolute way, since it is also influenced by other factors, 
such as intramuscular connective tissue proliferation. Therefore, histological and morphometric analysis is more reliable and indicated for evaluation of muscle condition and muscle fiber status ${ }^{25}$, even though we know of this, the data in this respect are still scarce.

In our result, it was observed that SVG and IOVG did not resemble CG, however, they presented higher morphometric results than DG. This is the main reason why one should not evaluate reinnervated musculature based only on muscle weight; in the muscle groups reinnervated groups were similar to the denervated, however were morphologically and morphometrically better.

The similarity of results between SVG and IOVG was also repeated in the analysis of the percentage of connective tissue, except for the fact that in the SVG soleus muscle was similar to CG, whereas in the EDL IOVG muscle was similar to CG. Between SVG and IOVG there was no difference in any of the muscles studied. This proliferation of the connective tissue is a common phenomenon in muscles submitted to denervation, this increase following denervation is due to the proliferation of type I and III collagen in the muscle, causing consequently the decrease of the elasticity impairing function and muscular quality, which can be Fundamental in the result of reinnervation ${ }^{26}$. This fact reinforces the difference between the result of muscular weight and the histological result, pointing out the importance of muscle morphometry when comparing denervated and reinnervated muscles.

We compared both grafts also in order to see which would offer better functional results, several studies have shown functional results, both with normal vein use ${ }^{18,20}$ and inside-out vein ${ }^{21-23}$, both acting favorably on functional recovery, but did not compare Both techniques. Among the comparative research,
Ferrari et al. ${ }^{27}$ compared standard vein graft to inverted vein graft on a sensory nerve, and there was no difference between groups (nerve morphology). Wang et al. ${ }^{28}$ also compared the standard vein and vein to the reverse on an (sciatic) motor nerve, reporting a better nerve regeneration with the inverted vein, but did not present a functional result.

\section{Conclusions}

In all evaluated aspects, there was no significant difference between SVG and IOVG, both grafts favored muscle recovery and improvement of functionality, however, the SVG achieved similarity to CG plus points, and IOVG was similar in more aspects to DG. Based on this, we concluded that the normal vein graft was the the best alternative among the options.

\section{- References}

1. Sunderland S. A classification of peripheral nerve injuries producing loss of function. Brain. 1951 Dec;74(4):491-516. PMID: 14895767.

2. Sunderland S. Nerves and nerves injuries. Edinburg: Churchill Livingstone; 1978.

3. Seddighi A, Nikouei A, Seddighi AS, Zali AR, Tabatabaei SM, Sheykhi AR, Yourdkhani F, Naeimian S. Peripheral nerve injury: a review article. ICNSJ. 2016;3(1):1-6

4. Kouyoumdjian JA. Peripheral nerve injuries: a retrospective survey of 456 cases. Muscle Nerve. 2006 Dec;34(6):785-8. PMID: 16881066.

5. Konofaos P, Ver Halen JP. Nerve repair by means of tubulization: past, present, future. J Reconstr Microsurg. 2013 Mar;29(3):14964. doi: 10.1055/s-0032-1333316.

6. Lundborg G, Richard P. Bunge memorial lecture. Nerve injury and repair - A challenge to the plastic brain. J Peripher Nerv Syst. 2003 Dec;8(4):209-26. PMID: 14641646.

7. Félix SP, Pereira Lopes FR, Marques SA, Martinez AM. Comparison between suture 
and fibrin glue on repair by direct coaptation or tubulization of injured mouse sciatic nerve. Microsurgery. 2013 Sep;33(6):46877. doi: $10.1002 /$ micr.22109.

8. Grinsell D, Keating CP. Peripheral nerve reconstruction after injury: a review of clinical and experimental therapies. Biomed Res Int. 2014;2014:698256. doi: 10.1155/2014/698256.

9. Battiston B, Geuna S, Ferrero M, Tos P. Nerve repair by means of tubulization: literature review and personal clinical experience comparing biological and synthetic conduits for sensory nerve repair. Microsurgery. 2005;25(4):258-67. PMID: 15934044.

10.Gonzalez-Perez F, Cobianchi S, Geuna S, Barwig C, Freier T, Udina E, Navarro $X$. Tubulization with chitosan guides for the repair of long gap peripheral nerve injury in the rat. Microsurgery. 2015 May;35(4):3008. doi: 10.1002/micr.22362.

11.Geuna $S$, Tos P, Titolo P, Ciclamini D, Beningo $\mathrm{T}$, Battiston $\mathrm{B}$. Update on nerve repair by biological tubulization. J Brachial Plex Peripher Nerve Inj. 2014 Mar 7;9(1):3. doi: 10.1186/1749-7221-9-3.

12.Zhang $P$, Han $N$, Wang $T$, Xue $F$, Kou $Y$, Wang Y, Yin X, Lu L, Tian G, Gong X, Chen S, Dang $Y$, Peng J, Jiang B. Biodegradable conduit small gap tubulization for peripheral nerve mutilation: a substitute for traditional epineurial neurorrhaphy. Int J Med Sci. 2013;10(2):171-5. doi: 10.7150/ijms.5312.

13.Sénès FM, Catena $N$, Sénès J. Use of tubulization (nerve conduits) in repairing nerve defects in children. Indian J Orthop. 2015;49(5):554-60. doi: 10.4103/00195413.164045.

14.Rodríguez FJ, Valero-Cabré A, Navarro $X$. Regeneration and functional recovery following peripheral nerve injury. Drug discovery today. Dis Models. 2004;1(2):17785. doi: 10.1016/j.ddmod.2004.09.008.

15.Bain JR, Mackinnon SE, Hunter DA. Functional evaluation of complete sciatic, peroneal, and posterior tibial nerve lesions in the rat. Plast Reconstr Surg. 1989 Jan;83(1):129-38. PMID: 2909054.

16.Chimutengwende-Gordon $M$, Khan $W$. Recent advances and developments in neural repair and regeneration for hand surgery. Open Orthop J. 2012;6:103-7. doi: $10.2174 / 1874325001206010103$.
17. Konofaos P, Ver Halen JP. Nerve repair by means of tubulization: past, present, future. J Reconstr Microsurg. 2013 Mar;29(3):14964. doi: $10.1055 / \mathrm{s}-0032-1333316$.

18.Demir A, Simsek T, Acar M, Aktaş A, Vlamings R, Ayyıldız M, Yıldırım M, Temel Y, Kaplan S. Comparison between flexible collagen and vein conduits used for size-discrepant nerve repair: an experimental study in rats. J Reconstr Microsurg. 2014 Jun;30(5):329-34. doi: 10.1055/s-0033-1356551.

19.Lavasani M, Gehrmann S, Gharaibeh B, Clark KA, Kaufmann RA, Péault B, Goitz RJ, Huard $J$. Venous graft-derived cells participate in peripheral nerve regeneration. PLoS One. 2011;6(9):e24801. doi: 10.1371/journal. pone.0024801.

20.Özkan HS, Karataş Silistreli Ö, Ergür B, İkören S. Repairing peripheral nerve defects by vein grafts filled with adipose tissue derived stromal vascular fraction: an experimental study in rats. Ulus Travma Acil Cerrahi Derg. 2016 Jan;22(1):7-11. doi: 10.5505/tjtes.2015.12612.

21.Mohammadi R, Azizi S, Delirezh N, Hobbenaghi R, Amini K. Functional recoveryof sciatic nerve through inside-out vein graft in rats. Chin J Traumatol. $2011 \mathrm{Feb}$ 1;14(1):46-52. PMID: 21276368.

22. Mohammadi R, Azizi S, Delirezh $N$, Hobbenaghi R, Amini K. Transplantation ofuncultured omental adipose-derived stromal vascular fraction improves sciatic nerve regeneration and functional recovery through inside-out vein graft in rats. J Trauma Acute Care Surg. 2012 Feb;72(2):390-6. PMID: 22439201.

23. Mohammadi $\mathrm{R}$, Amini $\mathrm{K}$, Eskafian $\mathrm{H}$. Betamethasone-enhanced vein graft conduit accelerates functional recovery in the rat sciatic nerve gap. J Oral Maxillofac Surg. 2013 Apr;71(4):786-92. doi: 10.1016/j. joms.2012.08.009.

24.Sabongi RG, Fernandes M, Dos Santos JB. Peripheral nerve regeneration with conduits: use of vein tubes. Neural Regen Res. 2015 Apr;10(4):529-33. doi: 10.4103/16735374.155428.

25.Salmons S, Ashley Z, Sutherland H, Russold MF, Li F, Jarvis JC. Functional electrical stimulation of denervated muscles: basic issues. Artif Organs. 2004;29(3):199-202. doi: 10.1111/j.1525-1594.2005.29034.x. 
26.Fernandes KCBG, Polacow MLO, Guirro RRJ, Campos GER, Somazz MC, Pinto VF, Fuentes $\mathrm{CB}$, Teodori RM. Análise morfométrica dos tecidos musculares e conjuntivo após desnervação e estimulação elétrica de baixa freqüência. Rev Bras Fisioter. 2005;9(2):23541.

27.Ferrari F, De Castro Rodrigues A, Malvezzi CK, Dal Pai Silva M, Padovani CR. Inside-out vs. standard vein graft to repair a sensory nerve in rats. Anat Rec. 1999 Nov 1;256(3):227-32. PMID: 10521781.

28.Wang KK, Costas PD, Bryan DJ, Jones DS, Seckel BR. Inside-out vein graft promotes improved nerve regeneration in rats. Microsurgery. 1993;14(9):608-18. PMID: 8289647.

\section{Correspondence:}

Mizael Pereira

Universidade de São Paulo

Faculdade de Odontologia de Bauru

Departamento de Anatomia

Alameda Dr. Octávio Pinheiro Brisolla, 9-75

17012-901 Bauru-SP Brasil

Tel.: (55 14)3235-8226

mizael.pereira@usp.br

Received: Dec 18, 2016

Review: Feb 15, 2017

Accepted: March 13, 2017
Conflict of interest: none

Financial source: CAPES
${ }^{1}$ Research performed at Department of Biological Sciences (Anatomy), Faculdade de Odontologia de Bauru, Universidade de São Paulo (FOB-USP), Bauru-SP, Brazil. 